\title{
Analytical Models for Delivery Performance of a Supplier or a Service Provider
}

\author{
M. Chandra Paul ${ }^{1}$, A. Vinaya Babu ${ }^{2}$, D. Mallikarjuna Reddy ${ }^{3}$, Malla Reddy Perati ${ }^{4 *}$ \\ ${ }^{1}$ Department of Computer Science, Kakatiya University, Warangal, India; ${ }^{2}$ Department of Computer Science Engineering, Jawaharlal \\ Nehru Technological University, Hyderabad, India; ${ }^{3}$ Department of Mathematics, GITAM School of Technology, Hyderabad Cam- \\ pus, Hyderabad, India; ${ }^{4}$ Department of Mathematics, Kakatiya University, Warangal, India. \\ Email: mcpaul1@yahoo.com, ${ }^{*}$ mperati@yahoo.com
}

Received August $8^{\text {th }}$, 2013; revised September $10^{\text {th }}, 2013$; accepted September $17^{\text {th }}, 2013$

Copyright (C) 2013 M. Chandra Paul et al. This is an open access article distributed under the Creative Commons Attribution License, which permits unrestricted use, distribution, and reproduction in any medium, provided the original work is properly cited.

\begin{abstract}
Delivery performance has evolved as an important metric in total quality management of an organization accredited with Lean Six Sigma and Capability Maturity Model (CMM) levels. Two analytical models are used to compute the delivery performance of an organization. One is deterministic and based on the number of days taken for the delivery and other is probabilistic and based on various stages of the product development which follow exponential distribution. For the second one cost effective analysis is made. This kind of analysis is very useful in the customer selection and appraisal of employee's performance.
\end{abstract}

Keywords: Delivery Performance; Lean Six Sigma; Capability Maturity Model; Exponential Distribution; Incomplete Gamma Distribution; Expected Penalty Cost

\section{Introduction}

Lean Six Sigma is a powerful cost effective and waste reduction process. For several years, it has been a good practice in both private and public market driven organisations. It is equally applicable in manufacturing industry and IT sector. Lean sigma has three components: 1) Six Sigma tools, 2) values and leadership and 3) customer oriented. These components are to guarantee the quality of service (QoS). On the other hand, capability maturity model (CMM) is a time tested framework to improve product quality in IT sector. There are five levels of CMM consisting of several key process areas (KPA's). One KPA at level 2 is supplier agreement and management to achieve the schedule. One of the Lean Sigma tools is 7 types of waste. One of these is waiting, for example, waiting for the request or specifications from the customer. Both frameworks Lean Sigma and CMM reveal that delivery performance plays an important role in total quality management (TQM) of an organization. According to the seminal study of Dickson [1], delivery performance is the third critical success factor (CSF) after quality and price. In the domain of supply chain management, delivery performance is cited as an impor-

\footnotetext{
"Corresponding author.
}

tant metric for supporting operational excellence of supply chain [2], and it is classified as a strategic level performance measure by Ganasekaran et al. [3]. In this direction, there are some empirical studies by da Silveira and Arkader [4], and Iyer et al. [5]. Above studies are confined to the domain of supply chain management. In the paper [6], cost effective analysis is made even for early delivery, because of inventory holding cost. This is not the case in the IT sector. In this paper, we employ two models, one is the deterministic model and other is the probabilistic model. In the first case, delivery performance depends on just number of days delayed. In the second case, delivery performance is probabilistic, it depends on the various stages of the product, and each stage follows an exponential distribution.

The rest of the paper is organized as follows: In Section 2, the deterministic model for delivery performance is employed. In Section 3, the probabilistic model for delivery performance is developed. Finally, numerical results and conclusions are given in Section 4.

\section{Deterministic Model}

In this section, we apply the formula [7] to compute over all delivery performance of a team. The following pro- 
cedure outlines the construction of delivery performance function which is based on the number of days taken to deliver a request from the day of assignment. This function should have the following properties:

1) Performance rate is 1 (that is, performance is $100 \%$ ) if a request is completed on or before the benchmark time.

2) After the target date, it is monotonic decreasing.

3) Values of this rate function lie between 0 and 1.

4) Being a rate function, it is differentiable.

Let $T$ be the target time to complete the request and $\phi(x)$ be the delivery performance rate function.

Mathematically, these conditions can be expressed as follows:

$$
\phi(x)=1 \text { for } x \leq T .
$$

For $x>T$, the function $\phi(x)$ should have the following properties:

$$
\begin{aligned}
& \phi^{\prime}(T)=0 \text { and } \phi^{\prime \prime}(T)<0 \\
& \text { (since } \mathrm{x}=\mathrm{T} \text { is a point of maxima, ideally) } \\
& \phi^{\prime}(x)<0 \text { for all } \mathrm{x}>\mathrm{T} \\
& \text { (since } \phi(x) \text { is a decreasing function). }
\end{aligned}
$$

We assume that delivery performance rate is zero if it takes more than double the target time to complete the request. Therefore, we have

$$
\phi(2 \mathrm{~T}+1)=0 .
$$

Now, we expand $\phi(x)$ using the Taylor series around $T$ and we obtain

$$
\begin{aligned}
\phi(x) & =\phi(T)+(x-T) \frac{\phi^{\prime}(T)}{1 !} \\
& +(x-T)^{2} \frac{\phi^{\prime \prime}(T)}{2 !}+\ldots . .
\end{aligned}
$$

Using (1), (2) in (4), we obtain

$\phi(x) \approx 1+(x-T)^{2} \frac{\phi^{\prime \prime}(T)}{2 !}$, neglecting the terms of order greater than two.

$$
\Rightarrow \phi(x) \approx 1+k(x-T)^{2}
$$

where $k=\frac{\phi^{\prime \prime}(T)}{2 !}$ is a constant depending on the target time $T$.

From (3) and (5), we have

$$
k=\frac{-1}{(T+1)^{2}} .
$$

Thus the function $\phi(x)$ takes the following form

$$
\phi(x)=\left\{\begin{array}{lll}
1 & \text { if } & x \leq T \\
1-\frac{(x-T)}{(T+1)^{2}} & \text { if } & T \leq x \leq 2 T+1 . \\
0 & \text { if } & x>2 T+1
\end{array}\right.
$$

\section{Probabilistic Model}

Software Development Life Cycle (SDLC) involves four successive phases namely: Requirements and Analysis, Design, Implementation \& Integration, and Testing. If each phase follows exponential distribution, then sum of all four phases follows Erlang k-distributions. Let $\mathrm{X}_{1}, \mathrm{X}_{2}, \mathrm{X}_{3}, \mathrm{X}_{4}$ be independent identically distributed random variables of the above four stages which follow exponential distribution with mean service time $\mu$. Then $\mathrm{X}=\mathrm{X}_{1}+\mathrm{X}_{2}+\mathrm{X}_{3}+\mathrm{X}_{4}$ follows Erlang - $k$ distribution $(k=4)$ and its probability density function is given by $f(x)=\frac{\mu^{k} x^{k-1} e^{-\mu x}}{k-1 !}$. If the benchmark time $x=c$, then the expected penalty cost for the late delivery is [6]

$$
\begin{aligned}
Y_{\text {late }} & =R \int_{C}^{\infty} \frac{(x-c) x^{k-1} \mu^{k} e^{-\lambda x}}{(k-1)} \mathrm{d} x \\
& =R\left[\int_{C}^{\infty} \frac{x^{k} \mu^{k} e^{-\lambda x}}{(k-1)} \mathrm{d} x-c \int_{C}^{\infty} \frac{x^{k-1} \mu^{k} e^{-\lambda x}}{(k-1)} \mathrm{d} x\right] .
\end{aligned}
$$

In the above equation, $R$ is penalty cost per unit late time. After simplification, Equation (7) is reduced to

$$
Y_{\text {late }}=\frac{R}{k-1 !}\left(\frac{1}{\mu} T(k+1, \mu c)-c T(k, \mu c)\right)
$$

where $T(\alpha, x)$ is the incomplete Gamma distribution given by the integral $T(\alpha, x)=\int_{x}^{\infty} e^{-t} t^{\alpha-1} \mathrm{~d} t$.

\section{Numerical Results and Conclusion}

Delivery performance rate against the number of days taken is computed using the Equation (6) in the case of deterministic model. The bench mark time $\mathrm{T}$ is taken to be 10 days. The numerical values are depicted in the Table 1 and the Figure 1. From the figure and table, it is clear that as the number of days taken increases, delivery performance rate decreases. Expected penalty cost for late delivery against mean service time $\mu$ is computed using the Equation (8) and the results are presented in the Figures 2 and 3. For the numerical process, MATLAB tool is used as the function, incomplete Gamma distribution is readily available in it. From the figures, it is clear that as the mean service time increases, expected penalty cost increases. Also, as the unit penalty cost and bench mark time increase, penalty cost increases. These results 
Table 1. Delivery performance rate against delay when the benchmark time is $\mathbf{1 0}$ days.

\begin{tabular}{|c|c|c|c|c|c|c|c|c|c|c|}
\hline $\begin{array}{r}\text { Benchmark } \\
\text { (Days) }\end{array}$ & 1 & 2 & 3 & 4 & 5 & 6 & 7 & 8 & 9 & 10 \\
\hline \multicolumn{11}{|l|}{ Delay } \\
\hline 1 & $75.00 \%$ & $88.89 \%$ & $93.75 \%$ & $96.00 \%$ & $97.22 \%$ & $97.96 \%$ & $98.44 \%$ & $98.77 \%$ & $99.00 \%$ & $99.17 \%$ \\
\hline 2 & $0.00 \%$ & $55.56 \%$ & $75.00 \%$ & $84.00 \%$ & $88.89 \%$ & $91.84 \%$ & $93.75 \%$ & $95.06 \%$ & $96.00 \%$ & $96.69 \%$ \\
\hline 3 & $0.00 \%$ & $0.00 \%$ & $43.75 \%$ & $64.00 \%$ & $75.00 \%$ & $81.63 \%$ & $85.94 \%$ & $88.89 \%$ & $91.00 \%$ & $92.56 \%$ \\
\hline 4 & $0.00 \%$ & $0.00 \%$ & $0.00 \%$ & $36.00 \%$ & $55.56 \%$ & $67.35 \%$ & $75.00 \%$ & $80.25 \%$ & $84.00 \%$ & $86.78 \%$ \\
\hline 5 & $0.00 \%$ & $0.00 \%$ & $0.00 \%$ & $0.00 \%$ & $30.56 \%$ & $48.98 \%$ & $60.94 \%$ & $69.14 \%$ & $75.00 \%$ & $79.34 \%$ \\
\hline 6 & $0.00 \%$ & $0.00 \%$ & $0.00 \%$ & $0.00 \%$ & $0.00 \%$ & $26.53 \%$ & $43.75 \%$ & $55.56 \%$ & $64.00 \%$ & $70.25 \%$ \\
\hline 7 & $0.00 \%$ & $0.00 \%$ & $0.00 \%$ & $0.00 \%$ & $0.00 \%$ & $0.00 \%$ & $23.44 \%$ & $39.51 \%$ & $51.00 \%$ & $59.50 \%$ \\
\hline 8 & $0.00 \%$ & $0.00 \%$ & $0.00 \%$ & $0.00 \%$ & $0.00 \%$ & $0.00 \%$ & $0.00 \%$ & $20.99 \%$ & $36.00 \%$ & $47.11 \%$ \\
\hline 9 & $0.00 \%$ & $0.00 \%$ & $0.00 \%$ & $0.00 \%$ & $0.00 \%$ & $0.00 \%$ & $0.00 \%$ & $0.00 \%$ & $19.00 \%$ & $33.06 \%$ \\
\hline 11 & $0.00 \%$ & $0.00 \%$ & $0.00 \%$ & $0.00 \%$ & $0.00 \%$ & $0.00 \%$ & $0.00 \%$ & $0.00 \%$ & $0.00 \%$ & $0.00 \%$ \\
\hline
\end{tabular}

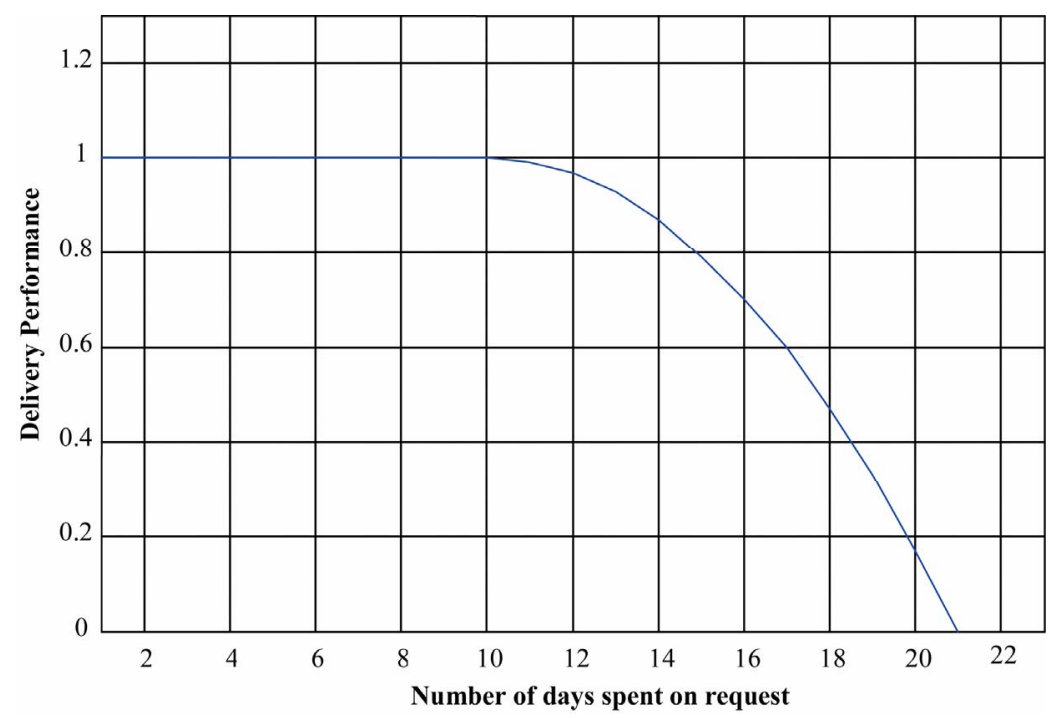

Figure 1. Delivery performance against the number of days taken when the benchmark time is $\mathbf{1 0}$ days.

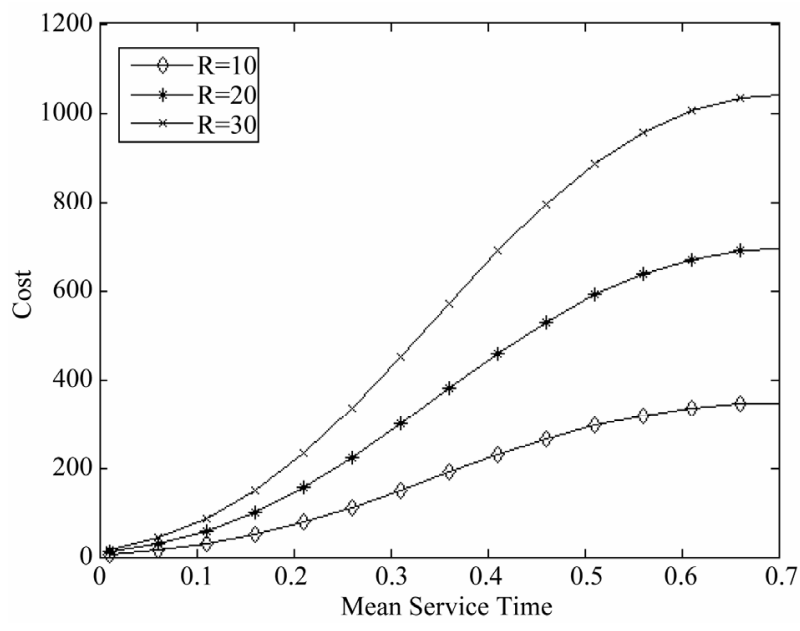

Figure 2. Variation of expected cost against service rate when benchmark time is 10 days.

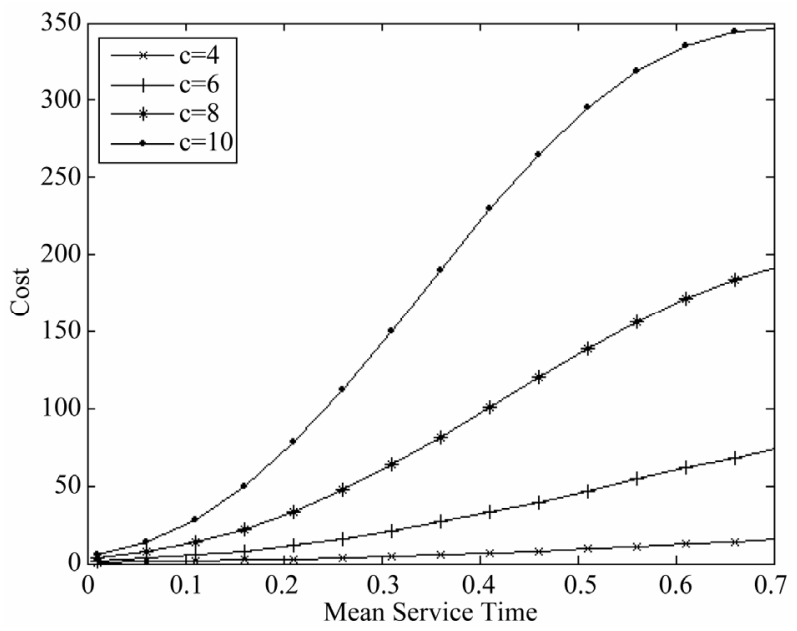

Figure 3. Variation of expected cost against service rate when the cost per unit delay (day) $R=10$. 
seem to be obvious; but in order to figure out the performance rate of employees for their appraisal, this kind of quantitative analysis is indeed.

\section{REFERENCES}

[1] G. W. Dickson, "An Analysis of Vendor Selection Systems and Decisions," Journal of Purchasing, Vol. 2, No. 1, 1966, pp. 5-20.

[2] The AMR Supply Chain Top 25 for 2010. www.gartner.com

[3] A. Gunasekaran and B. Kobu, "Performance Measures and Metrics in Logistics and Supply Chain Management: A Review of Recent Literature (1995-2004) for Research and Application," International Journal of Production Research, Vol. 45, No. 12, 2007, pp. 2819-2840. http://dx.doi.org/10.1080/00207540600806513

\section{MATLAB Program to Compute Expected Penalty Cost}

\% Cost Effective Analysis of Delivery Performance $\%$ Delivery time follows Erlong k-distribution \% Step-I (Input)

$\operatorname{cost1}=[]$

for $\mathrm{mhu}=0.01: 0.05: 0.71$

mhu = input (“enter mean service time mhu”)
[4] G. J. C. da Silveira and R. Arkader, "The Direct and Mediated Relationships between Supply Chain Coordination Investments and Delivery Performance," International Journal of Operational Research, Vol. 171, No. 1, 2007, pp. 140-158.

[5] K. N. S. Iyer, R. Germain and G. L. Frankwick, "Supply Chain B2B E-Commerce and Time Based Delivery Performance," International Journal of Physical Distribution and Logistics Management, Vol. 34, No. 7/8, 2004, pp. 645-661. http://dx.doi.org/10.1108/09600030410557776

[6] M. Bushuev, A. L. Guiffrida and M. Shankar, "A Generalized Model for Evaluating Supply Chain Delivery Performance," The 47th Annual MBAA International Conference, Chicago, 23-25 March 2011.

[7] M. R. Perati and M. R. Doodipala, "Two Performance Tools for Insurance Industry,” International Journal of Business and Management Tomorrow, Vol. 3, No. 6, 2013.

$\mathrm{R}=$ input (“enter penalty cost per unit late time”)

$\mathrm{C}=$ input ("enter bench mark time”)

\% Step-II (Computation)

Cost $=$

$\mathrm{R}^{*}\left((4 / \mathrm{mhu}) * \mathrm{C}^{*}\left(1\right.\right.$-gammainc $\left.\left(5, \mathrm{C}^{*} \mathrm{mhu}\right)\right)-\mathrm{C} *$ (1-gammai nc $\left.\left.\left(4, \mathrm{C}^{*} \mathrm{mhu}\right)\right)\right)$;

cost1 $=$ [service rate, cost $]$. 